\title{
FUENTES HISTORIOGRÁFICAS PARA EL ESTUDIO E INTERPRETACIÓN DE LOS MONTES Y SUS APROVECHAMIENTOS: SU APLICACIÓN EN CASTILLA Y LEÓN (SIGLOS XVI-XX) ${ }^{1}$
}

\author{
José María Ramos Santos \\ Instituto de Educación Secundaria de Sahagún (León)
}

\begin{abstract}
RESUMEN
Distintas fuentes historiográficas aportan una completa información para la historia forestal entre los siglos XVI y XX en Castilla y León. El empleo simultáneo de estas fuentes permite contrastar las diferencias existentes en la comprensión de la problemática ligada a los montes y a sus aprovechamientos forestales. Al mismo tiempo, estas fuentes ofrecen la oportunidad de comprobar una continuidad en el tiempo de los conflictos relativos al monte, y de las actuaciones destinadas a su conservación, conservación que va relacionada con la obtención de un beneficio económico a través de su explotación. Sólo desde la segunda mitad del siglo XIX, a través de los choques entre los Ayuntamientos y la Administración de Hacienda primero, y entre los Ayuntamientos y la Administración forestal después, se percibe un distanciamiento de las poblaciones rurales de la necesidad de mantener unos montes de los que están siendo privados, bien mediante la limitación de los aprovechamientos o mediante la desamortización.
\end{abstract}

Palabras clave: Pleitos, aprovechamientos, ganadería, Ordenanzas, roturaciones.

\begin{abstract}
A complete information for the study of the history of forests between the $16^{\text {th }}$ and $20^{\text {th }}$ centuries in Castile and Leon is provided by different historiographical sources. The simultaneous use of these sources makes possible to contrast the existing differences in understanding the problematic connected with tree-covered lands (woods) and the exploitation of the resources of those lands. At the same time, those sources give us the opportunity to verify a background of continuing conflicts in relation to the woods and the
\end{abstract}

1 El presente artículo corresponde unas primeras conclusiones de la Tesis Doctoral que se realiza en el Departamento de Geografía de la Universidad de Valladolid. La Tesis cuenta con una Beca a la Investigación concedida en el año 2003 por el Instituto de Estudios Zamoranos «Florián de Ocampo», dependiente de la Diputación de Zamora. 
proceedings intended for their conservation, conservation which is related to obtaining an economic benefit through its exploitation. Only from the second half of the $19^{\text {th }}$ century, through the disputes between Town Councils and the Taxes Administration first, and the Town Councils and the Forest Administration later on did the rural population become more distant of the necessity of maintaining some woods (lands) from which they were being taken away by the limitation of their exploitation or by the 'desamortización'.

Key words: lawsuit, (resources) exploitation, cattle raising, By-laws, ploughing.

\section{Introducción}

Un amplio conjunto de fuentes históricas resulta decisiva para una adecuada interpretación de la dinámica del paisaje vegetal. Estas fuentes documentales van desde los pleitos conservados en el Archivo de la Real Chancillería de Valladolid, los Protocolos Notariales de los Archivos Históricos Provinciales, las Ordenanzas y Libros de Actas conservados en los Archivos Municipales, el Catastro de Ensenada, las Relaciones Geográficas de Tomás López, las Cartillas y Cédulas declaratorias de amillaramientos y los Expedientes de Ventas de bienes nacionales, el Catastro de Rústica, y la amplia información procedente del IRYDA y del ICONA. A través de estas fuentes se puede seguir la compleja evolución de los cambios relacionados con el paisaje vegetal acontecidos en el mundo rural castellano-leonés.

Estas transformaciones manifiestan la vitalidad presente en el medio rural y el papel central que desempeña el monte en toda la Época Moderna y buena parte de la Edad Contemporánea. La intervención humana constituyó el detonante clave en la modificación del paisaje vegetal, tanto de manera voluntaria y premeditada como involuntaria, si bien fue más intensa, por los mayores recursos económicos y técnicos dispuestos, durante el período de tiempo que transcurre entre el siglo XVIII y el último cuarto del siglo XIX, cuando el proceso desamortizador había alterado sustancialmente la estructura de la propiedad rural, y había introducido importantes cambios en el modo de explotación de la tierra.

Comprobaremos en este artículo el interés que tuvo el monte para el campesinado, para los ganaderos y para los grandes propietarios, laicos y eclesiásticos, durante la Edad Moderna y el nuevo papel que adquirió el monte para las inversiones de capital durante el proceso desamortizador, y también para el campesinado a través de la roturación del mismo. Este proceso se seguirá a través de varias premisas:

- En el mundo rural del Antiguo Régimen el monte constituía una fuente de ingresos nada desdeñable para las poblaciones rurales o los grandes propietarios, tanto a través de la venta de la leña como del arrendamiento de los pastos, además permitía un aprovechamiento sistemático de los pastos por el ganado de los vecinos de los pueblos. Esto explica la existencia de una explotación racional de los recursos del monte, lo que no evitó abusos de distinto tipo, pero que en la medida de lo posible fueron perseguidos por los concejos afectados por los mismos. Así, en 1603 el concejo de Pinilla Trasmonte (Burgos) tala por el pie más de 50.000 encinas en el monte Carrascal, monte de común aprovechamiento con el concejo de Nebreda. Este concejo, en desacuerdo con esta actuación lleva a juicio al concejo de Pinilla y en 1606 el Tribunal de la Real Chancillería condena al concejo de Pinilla a respetar «las leyes y ordenanzas hechas a la conservación de los montes», y al pago de una indemnización de 400 ducados. El pleito es significativo de una problemática ligada a la 
explotación del monte, en torno a la cual se enfrentan intereses contrapuestos, que, en este caso resultan favorables a un respeto hacia el monte (ARCHVA, Pleitos Civiles, 1606).

- Los períodos de aprovechamiento de los pastos por el ganado estaban perfectamente reglamentados, así como el número de ovejas y cabras que podían entrar en el monte; las cortas del monte se fijaban en relación con las posibilidades del mismo, y atendiendo a las necesidades de la población en el caso de montes de propios, o en función del interés del propietario en el caso de montes particulares. Así, en la Dehesa de Valverde de Cerrato (Palencia) en 1752 la división del monte se realizaba en diez rozas, que se cortaban cada 14 años; cada año rentabilidad del monte ascendía a un total de 13.007 reales, que correspondían a 7.200 reales por los pastos, 5.457 por la corta de la leña y 300 más por la caza. En relación a las cortas se detecta un desigual tamaño de las mismas y un diferente estado del arbolado, pues entre la roza que genera más ingresos y la que genera menos ingresos la diferencia es de 1 a 8,5 (AHPPA, Libro 740, 1752).

- Esta lógica preocupación por controlar el aprovechamiento del monte llega al extremo de evitar el paso por las cercanías de la cabaña de la Mesta o de la cabaña de Carreteros sorianos. Tanto es así, que el aislamiento se percibe como una forma de salvación para el monte. En este sentido, cuanto el concejo de Castronuño plantea la necesidad de construir una nueva barca en el río Duero, en el sitio de la Rinconada, para cruzar de una orilla a la otra la Encomienda de San Juan protesta ante la Corona porque «por este medio se facilitaba el modo de poder traer las leñas de sus dehesas y hacer crecidas cortas sin poder proporcionar el modo para contenerlas...».

- Parece señalarse a lo largo de la segunda mitad del siglo XVIII una caída en el precio de los arrendamientos de pastos, dentro de las frecuentes fluctuaciones en el función de la abundancia o carestía de los pastos. Esta circunstancia de la depreciación del valor de los pastos se pone en relación con la crisis de la ganadería, pero quizás también con un ajuste de los precios al valor de mercado. Así, se comprueba en el caso de la dehesa de Carmona, que en 1752 fue arrendada en 16.000 reales por año, en 1760 en 16.500 reales, en 1771 y 1775 sólo se pagaron 12.500 reales por año para un número similar de ganado lanar, unas 6.000 cabezas, trescientas más o menos; finalmente el contrato firmado el 10 de octubre de 1787 ha caído hasta 10.900 reales (cifra que se mantiene hasta 1791), y el número de cabezas también ha descendido hasta 4.800 .

- La crisis de finales del siglo XVIII no hace sino reforzar el papel del monte en su doble aspecto de suministrador de materias primas, y de reserva de tierras para el cultivo temporal. No en vano a partir de la segunda mitad del siglo XVIII los Libros de Actas del Ayuntamiento de Valladolid están llenos de referencias a acotamientos de los montes, y limpieza o regeneración de los mismos. En definitiva, la mejora del monte es una garantía de futuro para la ciudad.

- La compra de montes desde la época del Trienio Liberal se justifica por el interés económico que estos grandes montes poseen para sus compradores, pues no sólo permiten un trasvase del capital que genera la explotación del monte a través del arrendamiento de sus recursos (muchas veces a los propios vecinos del pueblo que antes lo explotaban gratuitamente), sino que la posesión del monte permite la roturación del mismo para la puesta en cultivo de las tierras, dependiendo de la coyuntura económica. 


\section{El monte en la Edad Moderna: su interés económico y su extensión}

A través de los numerosos y extensos pleitos conservados en el Archivo de la Real Chancillería de Valladolid se puede comprobar la continuidad de los aprovechamientos en los montes (y de los conflictos y tensiones a ellos ligadas), prueba de la extensión del monte procedente de la época medieval y de la conciencia de que es un recurso frágil necesitado de una protección. En 1775 se falla en el Tribunal de la Chancillería un pleito entre el marqués de San Vicente y el concejo de Villaviudas por los aprovechamientos en el monte de Torrecilla, resultado de una disputa procedente de 1562. En este pleito se incluyen hasta tres apeos, correspondientes a los años 1584, 1653 y 1776, a través de los cuales se constata una dinámica positiva del arbolado de este monte desde 1563 hasta 1653 , y regresiva en el período que finaliza en el último apeo hecho en 1776. Esto puede corroborarse a partir del hecho de que en 1563, entre los 63 hitos señalados, en siete se marca un árbol (en seis ocasiones la carrasca o encina y en una ocasión el roble), mientras que en el apeo de 1653 hay 50 hitos y 21 de ellos (el 42\%) se ponen en un árbol (en 16 ocasiones son matas de roble o roble y en 5 ocasiones encinas o matas de encina). Finalmente, en el apeo de 1776 en los 46 hitos ya sólo aparecen dos menciones a árboles (una atalaya nueva y un roble). Si atendemos a esa evolución podemos concluir que, en este espacio del Cerrato palentino, el monte de la segunda mitad de siglo XVII se encuentra parcialmente desarbolado y en él predomina la encina sobre el quejigo, mientras que a mediados del siglo XVI el monte ha alcanzado una alta densidad de arbolado, preferentemente de roble, a partir del brote de raíz (ARCHVA, Pleitos Civiles, 1775).

La defensa de los intereses de un concejo en un monte sobre comunidades vecinas lleva a disputas de difícil solución. Entre 1623 y 1667 se dirime un complejo pleito entre el concejo de Montemayor de Pililla (Valladolid) y el de Cuéllar (Segovia) sobre el derecho al aprovechamiento de los pastos en el Monte El Carrascal y El Llano de la Pililla por parte de vecinos de Cuéllar. La defensa de Montemayor alega la propiedad de los terrenos de este monte, adquiridos en 1586 y plantados de pinar y monte de encinas y robles. Sobre este monte se aplicaron las Ordenanzas sobre montes de Felipe III aprobadas el 14 de julio de 1611 , que implican una alta protección para conseguir mantener y recuperar los montes en un radio de 10 leguas en torno a la ciudad de Valladolid.

El interés de estas Ordenanzas es indudable, en primer lugar porque se adelantan en el tiempo a la Instrucción de Montes de Pérez Bustamante (1656) y a la Instrucción de Antonio Contreras (1670), lo que revela su modernidad, en segundo lugar porque ponen de manifiesto la larga tradición existente en el mundo rural en relación con la conservación del monte, aspecto que se pone de manifiesto en la atención que se presta a la elección de la especie para cada terreno. Así, para la encina y el roble se prefieren los «tierras recias de barriales y barrancales», y para los pinares las tierras delgadas y arenosas, poco aptas para los cultivos.

También se presta atención a la época del año más propicia en que debe realizarse la siembra, de tal manera que se eviten las heladas en el invierno y los posibles fuegos en las épocas de más calor. La encina y el roble deben plantarse entre finales de octubre y diciembre, mientras que para el pino (pino piñonero preferentemente) los meses preferidos son los de marzo y septiembre. Finalmente, estas Ordenanzas inciden claramente en la conservación y aumento de los plantíos, con lo que ponen de manifiesto una práctica común en la ampliación de los encinares como montes bajos con el método de la plantación de bellotas. El turno de corta de tan sólo 15 ó 20 años no permite la formación de un monte alto, que, por otro lado no era el objetivo en el caso del encinar, pues lo que interesaba era el aprovechamiento de leña y pastos (ARCHVA, Pleitos Civiles, 1667). 
El problema de las intrusiones en los montes se perpetúa en el tiempo hasta bien avanzado el siglo XIX: La necesidad de madera se percibe como suficiente legitimación para los infractores. Así, fue frecuente que se alegase que un determinado monte era «monte de huida» (los asaltantes sólo serían llevados a la justicia si eran capturados en el monte con la madera cortada), como ocurría en el monte de Cubillas (Castronuño), para que los infractores sintiesen que se les daba una oportunidad de escapar y no ser llevados ante la justicia. La continuidad de los conflictos por el aprovechamiento de leña se comprueba en el complicado pleito que tuvo lugar en 1827 entre el concejo de Villahoz y el de Torrepadre, iniciado al acusar el primero de los concejos a vecinos de Torrepadre de entrar en el monte de Talamanca a talar y robar leña, deteriorándolo, lo que perjudicaba la conservación del pasto para el ganado, principal riqueza del pueblo (ARCHVA, Pleitos Criminales, 1827).

De igual manera, a través de otro pleito sabemos que el Monte Nuevo de Torresandino (Burgos), con 2.034 obradas, se sembró de encinas después de la Ejecutoria del año 1554 (nuevamente la siembra como método de ampliación de un monte), siendo adquirido por el concejo en las ventas de baldíos realizadas por la Corona en los años 1588 y 1592 . Esta ampliación de la superficie forestal en este espacio indica una decidida apuesta por la explotación forestal, en un terreno que en ese momento no ofrecía demasiadas posibilidades para la agricultura. También cabe pensar que sí había un importante interés agrícola, y lo que en realidad pretende el concejo realizando la plantación es preservar el monte como un bien de propios, pues el monte no podía, legalmente, ser cultivado. Junto a esta estrategia preservadora de un bien público el concejo persigue obtener unos saneados beneficios con su explotación.

El interés que ofrecen los montes para esta comunidad rural no eran nada desdeñables, no en vano en esa fecha de finales del siglo XVI ya había otros tres montes en explotación, dos de ellos encinares, la Dehesa de las Monjas del Monasterio de Santa María, y el Monte de Arriba del concejo; y uno más con sabinas, El Enebral, común para el Monasterio y los vecinos. De esta manera el aprovechamiento de los pastos y la leña por los habitantes del pueblo y las monjas del Monasterio, junto al arrendamiento de la corta de leña para carbón, y la venta de cortezas y raíces para los talleres de curtidores, constituyeron hasta bien avanzado el siglo XVIII un lucrativo negocio. Tanto es así que el comercio de carbón y de corteza de encina llegaba a poblaciones cercanas como Cevico Navero, o San Pedro de la Yedra, pero también a otras más lejanas como Fuentenebro, Palencia, a unos 50 Kilómetros o Villada a más de 110 kilómetros de distancia de Torresandino (ARCHVA, Pleitos Civiles, 1728).

\section{El siglo XVIII, entre la expansión de la agricultura y la lucha por la defensa del monte}

La entidad del monte en el siglo XVIII se conoce de una manera bastante aproximada a través del Catastro de Ensenada. Si a esta fuente añadimos los datos que proporcionan los pleitos de la Chancillería se puede completar un panorama mucho más exacto tanto de la extensión de los montes en Castilla y León, y de la dinámica roturadora de esta época, como de la estructura de los mismos. Así, un pleito de 1711 a causa de la corta fraudulenta de una pequeña superficie del Monte El Carrascal en Madrigal de las Altas Torres (Ávila) pone de manifiesto en primer lugar una práctica bastante frecuente en esta zona, y con un carácter definitivo, pues la encinas se arrancan de raíz, y, en segundo lugar, la existencia de un monte con una estructura muy densa, pues en las 2,4 hectáreas roturados se cortaron de 4.000 a 5.000 pies de encina, lo que da unos 2.000 pies por hectárea. El pleito de 1767 entre los concejos burgaleses de Valbuena y Castrogeriz por el aprovechamiento del monte El Interpre- 
tado se remonta a la misma fecha de su adquisición, en 1592, y permite comprobar el proceso de roturación realizado en partes del monte desde 1721 («se registran tierras rompidas y otras labradas... y algunas están entre matas de robles») (ARCHVA, Pleitos Civiles, 1767).

El deterioro de los montes, observado con fuerza en el siglo XVIII, y el aumento de las necesidades de pastos lleva a una creciente tensión sobre el monte; por lo que los propietarios intentan reducir las prácticas tradicionales de pastoreo alegando la destrucción del monte. Es lo que ocurre en el pleito que en 1750 mantienen el conde de Castrillo y el Convento de San Pelayo de Cerrato por los pastos de la dehesa de San Pedro de la Yedra, propiedad del primero. El conde acusa a los ganaderos por una parte de la corta ilegal de numerosos robles y encinas, lo que ha perjudicado la fabricación de carbón en el monte, y por otra parte de permitir la entrada en el monte de más de 1.000 cabras, lo que ha perjudicado notablemente la regeneración del monte. La sentencia de 1752 atiende las quejas del Conde y reduce la entrada de ganado del convento a no más de 80 cabezas de ganado vacuno (ARCHVA, Pleitos Civiles, 1750).

Cuando se trata de una dehesa el interés en la conservación del arbolado radica en que éste sirve para fijar el terreno sobre el que pueden pastar los ganados del propietario y los del concejo. Esto ocurre en Valderas (León) en 1702 cuando en relación a la Dehesa del Duque «de encinas afuera lo que corresponde al tercio de la villa todos los pastos que hay en él y sus aguas y demás aprovechamientos son propios del concejo», mientras que en la dehesa esos aprovechamientos pertenecen al señor de la villa. Esta circunstancia explica la escasez de pastos, por lo que los ganaderos de Valderas deben arrendar para pastos la dehesa de Castilfalé, la dehesa del monte de la Mata, Tardeconejos y Golpejar (ARCHVA, Pleitos Civiles, 1702).

Cuando se aspira a conservar un monte debe establecerse una estricta vigilancia, y así, por ejemplo en la repuesta $13^{\mathrm{a}}$ del Catastro de Ensenada los vecinos de Manganeses de la Lampreana, una población situada en plena Tierra de Campos zamorana, responden en referencia a su reducido monte de 105 hectáreas: «El monte alto... es propio del concejo de esta villa, quien lo guarda con todo rigor, bajo de varias penas, sin que en él permita hacer corta alguna, ni se ha hecho desde el año de 722, a fin de que se conserve para el abrigo de los ganados» (AHPZA, Catastro de Ensenada, 1754). La conservación del monte debe hacer incluso frente a la nobleza, que se aprovecha de su fuerza para vulnerar las normas generales sobre conservación de montes: En el pleito entre el concejo de Villahoz (Burgos) y el señor de Villahizán por la entrada de ganado en el monte Verdugal de Villahizán trasciende el hecho de la simple entrada en pastizales ajenos el hecho de que el monte Verdugal se encontraba en 1790 acotado para que se regenerase el arbolado de roble y encina, «con prohibición de entrada a todo género de ganado en cumplimiento de las repetidas Reales Órdenes expedidas sobre este particular» (ARCHVA, Pleitos Civiles, 1791).

Otras veces ocurre al contrario, la nobleza debe preservar sus montes de intrusiones de vecinos de pueblos próximos que, necesitados de pastos para sus ganados, entran en montes particulares reservados para la producción de leña. En 1796 se resolvió un pleito ante el Tribunal de la Chancillería entre la condesa de Castroponce y varios vecinos de Maire y Saludes sobre la entrada de estos con sus ganados en el monte de la condesa, acotado desde 1791. Resulta revelador del deterioro a que había llegado las relaciones sociales el que dos de los principales infractores sean el regidor de la villa de Maire y el cura de la villa de Saludes, y el que una razón de peso para vulnerar la prohibición pastar sea que los ganados de la condesa se hallaban pastando en el monte desde el 20 de enero (ARCHVA, Pleitos Civiles, 1796).

Los grandes Ayuntamientos tampoco pasan por alto el aprovechamiento del monte. A partir del 16 de noviembre de 1799 y durante varias semanas el Ayuntamiento de Valladolid 
debatirá la conveniencia de cultivar durante ocho años los terrenos del monte de Navabuena, en los Montes Torozos, para aumentar la superficie cultivada pero también para facilitar la eliminación de la plaga de langosta que durante el último año había afectado a los campos de la ciudad. A pesar de la oposición de los ganaderos de pueblos vecinos, especialmente Villanubla, por la reducción de pastos que implicaba esta operación, el Pleno municipal, tomando como ejemplo actuaciones similares en pueblos vecinos, solicitó licencia al Supremo Consejo para labrar 2.000 obradas (unas 1.100 has.) en el monte, con el objetivo de que después de los ocho años de cultivo el terreno se volviera a hacer monte. La difícil situación económica que atravesaba la población en el campo facilitó la concesión de la licencia por el Consejo Supremo, con lo que a principios de 1800 se puso en marcha la roturación del monte para «siembra de pan y legumbres» (Libro de Actas, 1799-1800).

Dos de los mejores exponentes de montes públicos objeto de un sistemático aprovechamiento son la Dehesa de Carmona y la dehesa de La Rinconada ambas en Castronuño (Valladolid), para las cuales se puede realizar un seguimiento desde principios del siglo XVIII hasta al menos 1828, tanto de los aprovechamientos que se realizaban en ellas como de la problemática ligada a esos aprovechamientos. En estas dehesas se realizaba un doble esquilmo, por un lado los vecinos del pueblo se beneficiaban de los pastos de verano, y por otro se arrendaban los pastos de invierno a ganaderos de pueblos próximos (Sieteiglesias de Trabancos, Nava del Rey y Alaejos) o a los carreteros de la Cabaña Real Soriana.

Dado el interés que tenía la Dehesa de la Rinconada para los propios vecinos en ocasiones se llegó a desahuciar a los arrendatarios de los pastos, como ocurrió en 1752 cuando se anuló el contrato de arrendamiento con los carreteros de la Cabaña Real, firmándose un nuevo contrato por cuatro años con un ganadero de Navaleno (Soria) en precio de 13.000 reales por cada año; pero en este contrato ya se estipulaba que los pastos de verano debían quedar para los ganados de labor de la villa de Castronuño (AHPVA, Protocolos, 1752). El problema había surgido cuando los carreteros introdujeron en el monte un número superior de cabezas de ganado de las que tenían autorizadas, en concreto 300 bueyes de más cada año.

En el aprovechamiento de estas grandes fincas no quedaba nada al azar. Así, por ejemplo, en el arrendamiento realizado en el año 1752 de los pastos de invierno, por un precio de 16.000 reales cada año, se admite la entrada en la dehesa de Carmona a 6.000 cabezas de ganado lanar desde el $1^{\circ}$ de octubre al 15 de mayo de cada año, pero fijando las zonas de la Dehesa que podían aprovecharse en cada momento durante esos siete meses y medio. De tal manera que los ganaderos arrendatarios sólo podían entrar con su ganado en el monte y las campiñas, pero no en los pastos de los prados, huertas y eras. A la vez que se destinaba el pasto de la Dehesa al aprovechamiento de pastos se realizaba un riguroso control de las talas, de forma que fueron frecuentes los pleitos contra vecinos de Alaejos, Sieteiglesias, Vadillo de la Guareña y San Román, por la corta y descepe de las encinas.

En 1773 el concejo de Castronuño plantea la necesidad de realizar una corta general en el monte de La Rinconada. La conveniencia de la corta se justifica por una serie de razones, unas de tipo productivista y de rentabilidad, y otras de mejora del arbolado, de lo que se sigue una innegable preocupación selvícola. Así, en un primer recorrido por la dehesa se constata el estado de envejecimiento de las encinas, por lo que «no fructifican de cuatro partes la una que deberían de dar bellota»; el motivo no es otro que el no practicarse las cortas en los tiempos oportunos, pues desde 1650 no se ha realizado corta alguna. La intención de realizar la corta en las mejores condiciones posibles para el arbolado lleva a que se emitan dos informes de los peritos para escoger el mejor método de corta. La diferencia entre ambos informes radica en el protagonismo que en uno se quiere otorgar a los pastos, mientras que en el otro hay un mayor interés por la producción de la bellota. 
Así, el primero de estos peritos montaraces es partidario de la corta dado el envejecimiento del arbolado, pero es contrario a la división de la dehesa en tres partes, y que de cada una se hagan diferentes quiñones. La razón no es otra que de esta manera la corta se prolongaría por espacio de doce años, lo que redundaría en perjuicio del arbolado, que no puede permanecer más de ocho o diez años sin recibir una corta de regeneración. La alternativa es la realización de una corta general en las 1.240 fanegas (620 has.) que están pobladas de encinas, reservándose los pastos de otras 649 fanegas (324 has.) en que apenas hay arbolado. Finalmente, en el monte cortado no deberán entrar por tiempo de seis años el ganado lanar y de cerda, y por tiempo de ocho años el boyal y cabrío.

El segundo informe defiende las tres divisiones porque de esa manera se podrán obtener unos ingresos superiores en el momento de la subasta, garantizándose la regeneración del arbolado en los tres quiñones en que queda dividido el monte; al mismo tiempo queda garantizado el aprovechamiento de los pastos de manera alternativa en los quiñones que van siendo cortados.

Esta segunda es la alternativa que finalmente se adopta, y su éxito parece innegable en cuanto a la obtención de leña y madera, pues de los 90.350 reales en que fueron tasadas las tres cortas el remate de la subasta (una vez concedida la licencia por el Superintendente de Montes y Plantíos) llegará hasta los 137.500 reales. Circunstancia que se explica por la carestía de madera existente en Castilla, pues el rematante es un vecino de Salamanca que debe surtir a las tropas asentadas en las ciudades de Zamora y Salamanca (AHPVA, Protocolos Notariales, 1776).

Las Ordenanzas antiguas de la villa de Valbuena de Duero (Valladolid), probablemente del siglo XVI, fijan con claridad tanto la división del monte de propios en 15 cortas como el sistema de explotación y la limitación a la entrada de ganado. Así, cada año se reparte una de las cortas o suertes entre los vecinos por iguales partes, con la expresa prohibición de que se saquen cepas o cepos de roble, para que no se perjudique la regeneración del arbolado. Por el contrario se permite que todos los vecinos «puedan cortar sin pena alguna y sin licencia de la justicia toda la leña de enebro que necesitasen». Esta circunstancia incide tanto en la progresiva eliminación de pies de Juniperus thurifera L., como en la preferencia que existe hacia el roble como especie más favorable para la obtención de leña, objetivo fundamental de este monte, pues en relación al ganado se establecen unas drásticas limitaciones que impiden, por un lado, entrar al ganado en los dos años siguientes al de la corta, y por otro hacer corrales o guardar ganado en el monte, y se fija un máximo de 1.900 cabezas de ganado las que pueden pastar cada año en el monte (1.200 ovejas, 600 cabras y 100 vacas) (AHPVA, Concejil, 1784: C. 238-19).

La preocupación por el estado del monte se comprueba en el estricto cumplimiento de realizar una corta por año, y en la obligación de volver a plantar robles o sembrar bellotas en los huecos que queden después de una corta, «guiando cuando convenga las matas o pimpollos que salgan» (AHPVA, Concejil, 1784: C. 238-1). El destino de este monte en el siglo XIX será doble, por un lado se producirá una reducción del mismo para su sustitución por pinares de repoblación, que alcanzan las 835 Has. en el año 1880 frente a 559 Has. de robledal, y por otro se mantendrá el aprovechamiento de carbón, leña, bellota y pastos, lo que pone de manifiesto el interés que sigue manteniendo para la economía del pueblo.

\section{Las desamortizaciones del siglo XIX y el cambio de timón en la gestión de los montes}

La puesta en marcha del proceso desamortizador a gran escala supone una ruptura en los aprovechamientos del monte y en la manera de gestionarlos. Desde 1821 con las primeras 
grandes desamortizaciones de propiedades de la Iglesia, y después, a partir de 1836, con la puesta en venta de todo tipo de bienes de la Iglesia, los grandes montes de numerosos monasterios salen a la venta y son adquiridos íntegros, formándose grandes propiedades. Así, el monte del Monasterio de Matallana y el del Monasterio de la Santa Espina se subastan en 1821. La venta de estas grandes fincas no supone un reparto de la propiedad de la tierra, y sí el inicio de un proceso de roturación de unos montes que hasta entonces habían sido explotados por los monjes para la obtención preferentemente de carbón.

Después de 1855, con la desamortización civil, el monte pierde el prestigio sobre el que se había sostenido hasta entonces, y es visto como la alternativa a la falta de tierras en el mundo rural. Los cambios en la economía agraria facilitan la ruptura de la relación que la comunidad rural había mantenido con unos montes que fueron durante mucho tiempo soporte de una frágil economía, sustentada en el máximo aprovechamiento de todos los recursos disponibles en el campo. En algunos casos la venta de estos montes de propios permitió el acceso del pequeño y mediano campesino a la propiedad de la tierra o al aumento de sus fincas, es lo que ocurrió con el monte El Rebollar de Nava del Rey, dividido en 99 suertes, o con el monte de Fresno el Viejo, dividido en 56 suertes, ambos en la provincia de Valladolid, en tierra de viñedos, y subastados entre enero y febrero de 1859. El destino de estos montes no podía ser otra que la venta para tierras de cultivo, pues el propio informe del ingeniero encargado del estudio del monte de Fresno confirma la degradación del mismo: «La única especie que le puebla es la encina, beneficiada en monte hueco, su repoblado es escasísimo, pues no contiene 18 encinas por hectáreas, las que son de mala configuración, envejecidas y con sus copas de pocas ramas» (AHPVA, 1859).

La ruptura del agricultor con el monte no se hizo de manera brusca, sino que es el resultado de un lento proceso de enajenación de los disfrutes del monte a través de su privatización, y de usurpación de tierras del monte para convertirlas en campos cultivados. De hecho, una tendencia muy marcada en numerosas poblaciones de larga tradición forestal consistió en la ocultación del terreno forestal, no sólo para evitar su incautación por el Estado sino también para evitar el pago de impuestos. Esta circunstancia no pasó desapercibida para la Administración de Hacienda, que puso todo su esfuerzo en evitar el fraude, como se refleja la Cartilla de Amillaramientos del año 1857 en Montejo de la Serrezuela (Segovia), donde Hacienda detecta «una ocultación de 7.842 obradas, de ellas 2.200 de monte y las 4.500 de inculta». La respuesta del Ayuntamiento no deja lugar a dudas sobre la intención ocultadora que existe en la corporación, amparada en la ausencia de documentación por parte de la Administración Central: «Las obradas señaladas de monte, o sea, chaparral de encina... no hay viviente que dé razón del tal monte..., las obradas señaladas de pinar no es posible que ni en el día ni en tiempos más remotos a la formación del Catastro haya habido el tal pinar y menos que su tierra sea aparente para ello» (AHPSG, 1857).

Esta doble dinámica se hizo muchas veces con el consentimiento o connivencia de los Ayuntamientos, que a través de la enajenación de unos bienes públicos obtenían recursos con los que sacar adelante sus magros presupuestos, al tiempo que daban satisfacción a las elites locales, muchas veces detentadoras del poder, o muy cercanas al mismo. La Administración Forestal conocedora de esta situación clama contra la impunidad en que se dejan muchos abusos cometidos en los montes; así, en la Memoria relativa a la ejecución del Plan de aprovechamientos forestales de 1874 a 1875 en el Distrito de Palencia el Ingeniero Jefe denuncia el desorden en los aprovechamientos del monte de Dueñas, achacándolo a

«la notoria arbitrariedad y escandaloso abuso que unos cuantos vecinos, mayores contribuyentes y de influencia en la provincia vienen cometiendo a la sombra de la venta de unas 217 hectáreas de monte que se llevó a efecto en $1869 .$. las cuales han 
ensanchado considerablemente y no sólo poseen y vienen aprovechando como lo tienen por conveniente, sino que no ha sido posible averiguar la cuantía de estos abusos por el interés que seguramente a todos reporta este estado de cosas.» (AMA, Planes Forestales, Caja 10).

No menos expresivo resulta el informe del ingeniero jefe del distrito forestal de Ávila, también del año 1875, cuando señalaba que la «excesiva acción abusiva de individuos dedicados a obrar según su libre voluntad, sostenidos cuando no fomentados por la falta de acción debida y aún acciones irregulares de los Ayuntamientos inmediatamente encargados de la conservación y fomento de dichos montes» (AMA, Planes, Caja 5). La incomunicación entre la Administración Forestal y los Ayuntamientos resultará decisiva en el deterioro de los montes, bien mediante su roturación o su falta de atención. Más aún, los pueblos desprovistos de un recurso del que se sienten propietarios no demandan más que un cultivo de las tierras del monte, para obtener un beneficio inmediato del monte.

El interés de los Ingenieros de Montes en poner remedio a la situación de desorden en los aprovechamientos llevará a una continua serie de enfrentamientos con la población rural, que degeneró hasta los primeros años del siglo XX en desórdenes públicos en numerosas localidades, lo que llevó a la Administración Forestal a paralizar determinadas actuaciones encaminadas a reducir el número de ganado que pastaba en los montes o a regular el volumen de leña cortada. El objetivo es crear montes con tranzones de las diferentes edades para conseguir un turno de corta regularizado. Ahora bien, en relación con el aprovechamiento de leñas y maderas en el monte los ingenieros continuaron manteniendo el turno de corta de 14 años para encinares y quejigares, lo que implicaba la división de estos montes en 14 cuarteles iguales. Sólo en aquellos casos en que la pequeña extensión del monte impedía la formación de ese número de cuarteles se mantenía el turno de 14 años pero sin darse corta todos los años. Cuando los Ayuntamientos vulneran esta práctica de una corta por año, algo que hasta la intervención de los ingenieros de montes en los montes públicos era algo frecuente, los Distritos forestales reaccionaban negando el año siguiente la corta correspondiente para restablecer el turno alterado. Así, por ejemplo el Distrito Forestal de Valladolid tuvo que adoptar esta medida en 1873 en los pueblos de Villavaquerín y Traspinedo.

Consciente la Administración de las limitaciones que encuentra en el desempeño de su labor por la fuerza de la tradición en el aprovechamiento de los montes de propios y comunes no ceja en reclamar el aumento de funcionarios, con mayor prestigio, y el apoyo de la Guardia Civil. Un mayor control no siempre resulta la solución para evitar la destrucción del monte, pues como ponen de relieve los ingenieros no es infrecuente el caso de subastas de monte para carboneo que quedan desiertas pues a los industriales les resulta más ventajoso contratar con los propios vecinos, que llegan a ejecutar las cortas incluso fuera de las épocas de la ordenanza, en los meses de mayo y junio para aprovechar las cortezas de las encinas.

Este fenómeno de las cortas fraudulentas debió estar tan extendido en la segunda mitad del siglo XIX como ya lo estuvo en los siglos XVII y XVIII, de tal forma que se señala la presencia de grupos organizados de matuteros que no sólo deterioran los montes al cortar los mejores árboles, sino que al sacar al mercado madera y leña en cualquier época provocan caídas de precios en los mercados locales, lo que va en detrimento de los remates públicos. La razón de este aumento de las infracciones ha de buscarse también en un aumento de la demanda de madera de buena calidad, especialmente para las traviesas de las distintas vías férreas que a lo largo de los años 70 y 80 se construyen en toda Castilla y León, pero también para los útiles de labranza en una época en la que aumenta la producción agraria. 
El proceso de la enajenación de los patrimonio públicos fue lento, y no estuvo exento de contradicciones. Así, aunque el 9 de abril de 1845 el Ayuntamiento de Palencia acordó la venta del Valle de San Juan para costear la construcción de una nueva Casa Consistorial, esto tan sólo supuso la pérdida de una pequeña parte del rico patrimonio municipal. De tal manera que este Ayuntamiento continuó durante las décadas de 1860 y 1870 con el recurso de conceder a partir del 15 de diciembre a todos los braceros de la ciudad el disfrute de una roza en el Monte El Viejo. El aprovechamiento se realizaba bajo unas estrictas condiciones que pretendían evitar el fraude; así las condiciones repetidas todos los años con pequeñas variaciones determinan que:

- Para facilitar el control sólo se podrá subir al monte de día, y el único punto para acceder a la ciudad será el Puente Mayor, donde se colocará una romana para el pesaje de la leña.

- Los vecinos que tengan caballería abonarán un real y 50 céntimos.

- Sólo se permitirá el transporte de entre 8 y 10 arrobas (de 92 a 115 kilos) con caballería menor y hasta 16 con caballería mayor, por cada día. Los acegeros o braceros podrán transportar hasta 6 arrobas.

- A los guardas o vecinos de los colmenares sólo se les permitirá acopiar 200 arrobas de leña.

Este disfrute del monte por la clase obrera era paralelo a los otros dos aprovechamientos que se subastaban todos los años: Los pastos y la corta de una roza cada año. Los pastos eran aprovechados por ganado lanar, mular o caballar entre el 15 de noviembre y el 15 de marzo (o entre el $1^{\circ}$ de diciembre y el 30 de marzo) con la condición de que el ganado lanar podía pastar en todas las rozas, pero el mular o caballar en ocho de las catorce en que se dividía el monte (Ciego, Torno, Carropluma, Beato y Buentrigo). Estas catorce rozas permitían al Ayuntamiento obtener cada año unos ingresos de casi 7.000 reales, cifra que variaba de unos años a otros, pues las rozas se arrendaban independientemente, y para cada una se fijaba un precio, que en 1870 iba desde 180 reales hasta los 820 . Diferencias que están en relación con el tamaño de la corta pero también con el estado de conservación del arbolado y por consiguiente del pasto. La orientación del monte hacia la producción de leña hace que el número de cabezas de ganado que puede sostener se vean reducidas, así en 1848 las 11 rozas que se arrendaron para pasto sólo permitieron mantener a 2.300 cabezas, cifra baja si tenemos en cuenta que otras dos rozas del Monte Nuevo dieron cabida a 1.250 cabezas. No en vano la corta de una roza por año suponía los mayores ingresos del monte.

El arrendamiento de una o dos rozas cada año suponía un ingreso nada desdeñable para el Ayuntamiento. Así, la corta de la roza de la Gitana en 1847 ofreció 1.243 carros de leña, que a 8 reales el carro elevó la cuantía percibida a 9.949 reales.

Otra situación en la que se constata una precisa regulación de los esquilmos en el monte es la que tiene lugar el Coto de Matallana (Valladolid). En 1823, poco después de la compra de este coto, localizado en los términos de Matallana y Villalba del Alcor, su propietario arrienda todas las tierras en la cantidad de 120.000 reales. En este contrato se fijan con claridad los cuatro aprovechamientos a los que tienen derecho los arrendatarios, que consisten en la labranza de las tierras, los pastos, la leña y la percepción de la renta de los granos que deben pagar diferentes campesinos. En el contrato de fijan con suficiente claridad unas estrictas condiciones que garantizan el mantenimiento del monte y evitan el sobrepastoreo, de tal manera que el incumplimiento de las mismas comporta fuertes penas pecuniarias: 
- Los arrendatarios sólo podrán cortar leña y fabricar carbón en el monte Carrascalejo y en cinco de las 19 cortas en que se divide el monte (Picón de San Martín, Raso de la Plaza, Carezos, Navillas y Corrales).

- La época de corta de leña queda limitada al período de primeros de noviembre a al 15 de marzo.

- La técnica de corta ha de ser a uña el roble y a uña y codo la encina.

Cuando el contrato de arrendamiento sólo afecta a los pastos, se fija con claridad el tipo de ganado que se aprovechará de este esquilmo. Así, en el arriendo del monte Sardonedo en Valdenebro de los Valles (Valladolid) en 1841 por espacio de cuatro años se establece la prohibición de la entrada en cualquier tiempo de ganado vacuno y cabrío por el perjuicio que ocasionan al arbolado.

Ahora bien, en la segunda mitad de este siglo XIX se manifiesta con claridad una ruptura en la relación del hombre con el monte. Así, puede verse cómo se ha recorrido un largo camino entre la corta de regeneración del monte de La Rinconada en 1773, o la roturación de 1799/1800 en el monte Navabuena (Valladolid) para conseguir su mejora, y la corta de 1854 para la eliminación del monte de La Frausilla (Dueñas), o la venta en 1875 de 7.000 quintales de tierra en el monte Navabuena para su cultivo.

Un ejemplo bien expresivo de la nueva época se aprecia en el Monte citado de La Frausilla. En mayo de 1854 se procede a la firma de un contrato de descuaje y corte del monte de La Frausilla en Dueñas por valor de 70.000 reales. Esta corta del monte resultará una compleja operación que se prolongará hasta el 31 diciembre de 1856, fecha en la que «ha de quedar todo el suelo libre de carbón, leña y cualquiera otro aprovechamiento». En definitiva, el destino de este monte no es otro que el convertirlo en tierras de cultivo, por lo que no ha de quedar ninguna raíz y tan sólo se dejarán seis atalayas para el propietario. De esta forma, el monte se divide en seis zonas, y ha de cortarse alternativamente una de las que miran a la raya de Dueñas con otra de las que lindan con la raya de Cubillas; con este sistema se trata de garantizar una corta regular de todo el monte, para que el propietario pueda poner en cultivo la tierra roturado. No en vano, la corta del monte en tres años implica la entrega cada año de dos suertes al propietario para su puesta en cultivo (AHPVA, Protocolos Notariales, 1854).

\section{El monte continúa su agonía en el primer tercio del siglo XX. El ciclo se cierra después de 1939}

Entre finales del siglo XIX y el primer tercio del siglo XX muchos montes se dan por perdidos y se acepta su destino como tierras de cultivo. Hasta la propia Administración Forestal, reconociendo sus errores pasados, admite la reducción de la superficie forestal ante la fuerza de las reivindicaciones vecinales. Así, por ejemplo, cuando entre 1915 y 1920 los vecinos de Montemayor de Pililla solicitan un aumento de la superficie cultivable en el Monte Llano de la Pililla, monte declarado de Utilidad Pública e inscrito en el Catálogo con el número 64, la Administración Forestal inicia una verdadera batalla en contra de esta pretensión, pues su objetivo es la reforestación de este monte. Ahora bien los ingenieros no dejan de mostrar su desánimo, y como afirma uno de ellos:

«¿Cómo se puede exigir a esta Administración que año tras año siga denunciando la misma roturación y siga prestándose a la mofa de los roturadores?. Concluye por donde tiene que concluir, por dejarles en paz... Por todo ello, entiende el que dice, que la Administración hoy debe allanarse ante la realidad, ante la fuerza de las circunstancias». 
La situación existente en 1915 no era sino el resultado de un lento proceso de enajenación de terrenos del monte, proceso que, paradójicamente, se inicia tras la inclusión del monte en el Catálogo de Montes de Utilidad Pública. En ese momento, de manera harto significativa, se pierden algo más de 700 hectáreas: Si la gestión del monte ya no pertenece al pueblo al que pertenece el monte, los vecinos se sienten legitimados para usurpar lo que les ha sido usurpado a ellos. De esa manera el monte queda reducido a 2.272 hectáreas, que se dividen en dos cuarteles, el A con 1.121 hectáreas está completamente roturado, mientras que el B, de 1.150 hectáreas tiene pobladas 470 hectáreas. En 1915 un $70 \%$ de la superficie se dedica a tierras de cultivo (1.579 hectáreas) y otro $30 \%$ a pinar de pino negral (444 hectáreas) y encinar (200 hectáreas).

En los años siguientes continúa este largo conflicto entre el Ayuntamiento de Montemayor de Pililla (Valladolid) y la Administración Forestal en relación al destino del monte Llano de Pililla de 2.272 hectáreas: En 1918 los vecinos remiten al Ingeniero Jefe del Distrito un informe en el que solicitan se les condone el canon impuesto por la legitimación de roturaciones. De hecho la aplicación de este canon es la reacción de la Administración Forestal a los reiterados fracasos por conseguir la repoblación del monte, con lo que sólo encontró como solución aplicar el canon por cultivo de parcelas en el monte. Por este motivo la respuesta del ingeniero encargado de emitir el informe de respuesta no puede ser más contundente en la defensa del monte frente a una agricultura poco rentable y una situación económica injusta de por sí, pues la roturación ha provocado una desigual distribución de tierras, de forma que mientras hay 101 agricultores que sólo labran media hectárea otros 11 labran casi 37 hectáreas cada uno:

«Lo que procede no es rebajar ni condonar el canon impuesto sino dejar las tierras cuyo cultivo no sea económico para que vuelvan a ser lo que fueron antes de haber sido inicuamente taladas, magnífico monte, con la renta de cuyo resto sólo (444,4 has. de las 2.272 que tiene la finca) cubre hoy día el pueblo dos veces el presupuesto» (AHPVA, 1918).

Transcurrido el tiempo, en 1940 la superficie cultivada se ha reducido a 1.377 hectáreas, que repartidas de una manera equitativa (en este aspecto las cosas han cambiado con respecto a la situación de 12 años atrás) entre los 400 vecinos del pueblo dan a tan sólo 3 hectáreas por vecino, lo que no modifica de manera sustancial el tamaño de la explotación media de los propietarios del pueblo. Sobre este monte se realizará en 1952 una distribución de parcelas sobre 814 hectáreas del monte para su cultivo que pone punto y final a la secular disputa entre la Administración forestal y la población de Montemayor (AHPVA, ICONA, 1952).

El monte Carboneros y Pico del Águila de San Miguel del Arroyo (Valladolid) fue el centro de otro grave conflicto de 1905 a 1916 entre los vecinos y la Administración Forestal. Los vecinos alegan para acabar de roturar el monte dos razones: En primer lugar argumentan que el monte fue adquirido por sus antepasados en 1586 «para que libremente lo pudieran labrar, sembrar y cultivar»; en segundo lugar mantienen que este monte al encontrarse en su mayor parte sin arbolado es mejor y más beneficioso reducirlo a terreno labrantío. Esta reflexión coincide en término generales con la opinión cada vez más extendida en el campo proclive a un aumento de la superficie cultivada: Este monte (incluido en el Catálogo de Montes de Utilidad Pública en 1901 con el número 53) de 2.000 hectáreas en 1905 sólo conserva arboladas 300 hectáreas, habiendo sido roturadas las restantes a partir de 1870 (AHPVA, 1916).

Estos conflictos por la dedicación a cultivo de una parte del monte público fueron algo frecuente en el primer tercio del XX, resolviéndose con frecuencia con la concesión de las 
solicitudes formuladas por el Ayuntamiento, en la esperanza de que con el tiempo las tierras fuesen abandonas debido a las malas cosechas y pudiesen retornar al monte. Esto es lo que sucedió con el Monte de La Villa en Dueñas, donde desde 1927 se siembran cada año 1.200 hectáreas; en el Monte de Tariego se cultivan 150 hectáreas, en el Monte de la Cruz Alta de Castrillo de Don Juan se labran 120 hectáreas desde 1929 (AHPPA, Hacienda, 1931). En el Monte Las Liebres en Valdenebro de los Valles (Valladolid) se cultivaron entre 1918 y 1946 una superficie variable desde las 320 a las 450 hectáreas de las 901 que ocupaba la totalidad del monte. A pesar de la negativa de los ingenieros a ampliar la superficie cultivada en 140 hectáreas, los vecinos obtuvieron en 1941 la concesión para roturar y cultivar hasta un máximo de 450 hectáreas.

Ante la solicitud de roturación del monte Ontorio en La Parrilla en 1931 el Ingeniero Jefe del Distrito estima poco creíbles los argumentos del Ayuntamiento, en el sentido de que el cultivo de 150 hectáreas de monte, de mala calidad, en poco o nada alterarían la vida económica del pueblo. En cualquier caso, ante la situación de enfrentamiento existente es partidario de una solución intermedia, consistente en: Autorizar a cortar tres tranzones del monte para darlos en cultivo, aclarar otros tres tranzones para dejar 150 pinos por hectárea, y repoblar artificialmente los cuatro tranzones restantes. Así, al menos se recupera una parte del monte, en espera de reforestar el resto.

Estos repartos de tierra, una vez concedidos por la Administración, dieron lugar a no pocas injusticias, pues el reparto pocas veces era igualitario: Se perpetuaba de esta manera una práctica que era habitual en los repartos de tierras en el siglo XIX. Así en el reparto de 1931 del Monte de Abajo 300 hectáreas se repartieron entre los 30 mayores propietarios, que poseían explotaciones de entre 10 y 16 hectáreas, con lo que aumentaron su explotación media en unas 8 hectáreas, mientras que los otros 42 agricultores no recibieron nada. ¿Cuál es la explicación de este hecho? La razón es bien sencilla, y es que en 1914 se había solicitado un préstamo cuyos interés y amortización pagaban todos los agricultores que participaban en el reparto, lo que había permitido marginar a los agricultores más pobres que no disponían para el dinero del préstamo, y por tanto tampoco para disfrutar del cultivo de la tierra (ICONA, 1931).

La necesidad de ampliar la superficie cultivada cada año se explica fácilmente en el informe que emite el Ayuntamiento de Cevico de la Torre en 1931: Desde varios años antes se destinan a cultivos 680 hectáreas en el monte Del Común, con una superficie de 970 hectáreas, pero cada año sólo se labran la mitad de esa superficie, o sea 340 hectáreas, «por hallarse casi totalmente esquilmado el terreno por haber sido labrado y sembrado desde la concesión continuamente, se hace preciso la alternativa barbechera la siembra» (AHPPA, Hacienda, 1931). No pocas veces esos repartos generaban un intento de apropiación vecinal de la tierra, así ocurrió en 1925 cuando los vecinos de Torrescárcela beneficiarios en el reparto para roturación y siembra de las 600 hectáreas del monte Paradero, tomaron la decisión de solicitar en la Delegación de Hacienda la legitimación de esas parcelas como roturaciones arbitrarias, amparándose en el Reglamento de 2 de febrero de 1924 que desarrolla el Real Decreto de 1 de diciembre de 1923 sobre legitimaciones de posesión de terrenos roturados por particulares o cedidos indebidamente a estos por los Ayuntamientos. Esta decisión provoca el rechazo del Ayuntamiento y de otra parte de los vecinos no usufructuarios del monte, pues parece claro que lo que está detrás de este intento es una usurpación de un bien público (AHPVA, Hacienda, 1931).

Los conflictos por los aprovechamientos en los montes se prolongaron hasta los años 70 , cuando ya la población rural había descendido de manera ostensible, lo que pone de manifiesto el arraigo del monte como recurso propio de los pueblos, al margen de los intereses de la Administración Central. Arraigo que no implica necesariamente conservación, pues es 
continua la utilización del monte para ampliar la superficie de cultivo. Más aún, en la época de 1941 a 1960, en la que la Administración Central intervino con intensidad a través del Instituto Nacional de Colonización en el medio rural para resolver el problema del reparto de la propiedad en algunas zonas, el recurso tanto a la expropiación de montes privados, previo pago de una indemnización, como a la compra de los mismos por ofrecimiento de sus propietarios, señalará el final para muchos montes.

\section{Debate y conclusiones}

Durante el siglo XVI parece señalarse en amplias zonas de Castilla y León una extensión de la deforestación que provoca la desaparición del monte. Esta circunstancia se constata en las descripciones de viajeros europeos que recorren las tierras castellanas y destacan la ausencia de montes y la falta de leña; es lo que hace Laurent Vital: «En Tordesillas la leña es muy cara, porque los bosques están lejos, a más de dos jornadas, por lo cual, al que la quiere tener, le es preciso enviarla a buscar con gran coste de carretas o mulo; por lo cual tienen costumbre de usar leña de sarmientos de viñas, a causa de que están más baratos. Pero la leña gruesa es para los señores y gentes de bien que están en situación de pagarla.» (García Simón, 1999: 23).

Esta tendencia roturadora, que reduce los pastos para el ganado, hace que entre los siglos XVI y XVII sean frecuentes los pleitos que entabla el Concejo de la Mesta con los concejos de distintas localidades y con propietarios particulares por la roturación y siembra de los montes por cuyas proximidades pasan las cañadas. Es el caso de los pleitos que entabla este Concejo ante la Real Chancillería de Valladolid: En 1555 contra dos vecinos de Palenzuela (Palencia) por ocupación de una dehesa; en 1579 contra los concejos vallisoletanos de Nava del Rey, Medina del Campo y Pollos por la roturación del monte Valdemuelles y la Dehesa del Palancar (ARCHVA, Pleitos Civiles, 29-2); en 1584 contra el concejo palentino de Vertabillo por haber roturado un terreno que era dehesa (ARCHVA, Pleitos Civiles, 341-1); en 1586 contra el conde de Villanueva por destinar a labranza unas tierras de la Dehesa de Villaester (Valladolid), reclamadas como tierras de pasto por la Mesta (ARCHVA, Pleitos Civiles, 858-1); en 1588 contra varios vecinos de Támara por labrar tierras en la Dehesa de Villafruela (Palencia) (ARCHVA, Pleitos Civiles, 1.141-1); en 1589 con el concejo de Toro (Zamora) y los guardas de los montes de Val de Iniestas, El Pego, Bardales, la Reina por no impedir roturaciones (ARCHVA, Pleitos Civiles, 541-1); en 1607 contra el marqués de Aguilafuente por la roturación de unas tierras en la Dehesa de Valverde (Palencia) (ARCHVA, Pleitos Civiles, 1.819-1); en 1617 contra los arrendatarios de la dehesa de Las Gordillas (Ávila), propiedad del convento de Santa María de Jesús por haber roturado parte de la misma en zonas de pasto.

El pleito de 1617 puede ser bien expresivo de una constante en este tipo de casos: El Concejo de la Mesta denuncia a varios renteros de la dehesa de Las Gordillas por haber roturado tierras de monte (un total de 300 obradas) para su cultivo. Las denuncias son dos, una de 1617 y otra de 1621; y aunque en los dos casos el alcalde mayor entregador condena a los renteros, estos interponen recurso ante el Presidente y Oidores de la Real Audiencia de Valladolid, viéndose apoyados por el convento, más interesado en el cultivo de las tierras que, de esa manera, le proporcionan mayores ingresos.

Con no menos frecuencia actuó el Concejo de la Mesta contra los nobles y los arrendatarios de sus montes y dehesas, como se comprueba en el pleito que en 1632 siguió la Mesta contra el conde de Castronuevo de los Arcos (Zamora) por haber permitido roturar y labrar la dehesa de Las Vegas. En esta ocasión la resolución del pleito no pudo ser más desfavorable a los intereses de la Mesta, al revocar la Audiencia de Valladolid la sentencia del alcalde entre- 
gador de la Mesta y aceptar las argumentaciones del conde y su arrendatario, en relación a que la dehesa se llevaba roturando y cultivando más de 32 años, y ya en 1607 se había fallado otro juicio favorable a los intereses del propietario (ARCHVA, Pleitos Civiles, 2.241-3).

Ahora bien, esta aparente situación de deforestación no siempre conducía a la desaparición definitiva del monte, sino que éste podía volver a recuperarse al cabo de algunos años. Por otra parte no cabe pensar en una sistemática destrucción del monte, pues son frecuentes las referencias a la protección del monte frente a la entrada de ganaderos o frente a la roturación del mismo. Así, ni tan siquiera en el caso de Tordesillas parece confirmarse la destrucción del monte para finales del siglo XVI, pues al Sur del río las monjas de Convento de Santa Clara poseían el preciado y extenso monte de Terradillos, preservado de las roturaciones por ser un monte del Patrimonio Real. De hecho, a lo largo de todo el valle del Duero los montes de pinos y encinas eran la norma y no la excepción. En la cercana zona de La Seca, recorrida en 1592 por el escritor inglés Enrique Cock, pudo constatar todavía la existencia de un extenso monte: «Acabada la comida, fue su majestad por el camino a caza de conejos por haber buen monte y bosques en él, y la compañía le iba aguardando junto a una ermita en la ribera del Duero» (García Simón; 1999: 281).

En el siglo XVIII se ha apuntado una continuidad en el proceso roturador (Sánchez Salazar, 1982: 227 y ss.), que ni siquiera la crisis de la ganadería lanar a finales de siglo puso freno, pues la agricultura demandó cada vez más tierras tanto para sembrar cereales como para plantar viñedos, circunstancia que es perfectamente observable en la zona de Toro (Zamora), donde entre finales del siglo XVIII y el primer cuarto del siglo XIX se roturan y parcelan los montes al Sur del Duero (Monte de las Contiendas y Monte de Bardales), con lo que el Ayuntamiento percibe anualmente el canon por cultivo de tierras, de ahí la permisión en la práctica de estas roturaciones.

El comienzo del proceso desamortizador cuenta con el beneplácito de la burguesía comercial y financiera de las ciudades, pero también con la aquiescencia de buena parte de la población rural, especialmente aquellas con ciertos recursos económicos, que ve en la venta de bienes de la Iglesia un método para incrementar sus propiedades. Sólo el comienzo de la desamortización civil de Madoz en 1855 levantará oposiciones en el mundo rural, pero de manera diferenciada por zonas. En una primera época el apoyo a la desamortización parece bastante generalizado por los beneficios que reporta a los Ayuntamientos, e incluso periódicos de talante agrarista se lanzan a una campaña en defensa del proceso y de la mejora del mismo para que los propietarios no se vean perjudicados al tener que hacer frente a los censos que graban las grandes propiedades. Es lo que hace El Norte de Castilla, publicado en la ciudad de Valladolid, en el mes de agosto de 1865. No pocos Ayuntamientos emprenden ya en los años 60 una defensa jurídica de sus montes, que se irá diluyendo ante las dificultades para llevarla a buen término, pues pocos municipios cuentan con recursos suficientes, y el monte se convierte cada vez más en un espacio sobre el que aumentar las tierras cultivadas: A finales del siglo XIX todavía se han preservado extensas zonas arbolados, en diferente estado de conservación, pero generalmente en las zonas de inferior interés para la agricultura, e incluso en el primer cuarto del siglo XX el afán roturador hará peligrar estas reservas forestales a despecho de una agricultura insaciable en sus necesidades de tierras, que no de mejoras técnicas.

\section{Referencias bibliográficas}

GARCÍA SIMÓN, A. (editor) (1999): Castilla y León según la visión de los viajeros extranjeros (siglos $X V$-XIX). Edita Junta de Castilla y León. Consejería de Educación y Cultura. Salamanca, 382 páginas. 
SÁNCHEZ SALAZAR, F. (1982): «Los repartos de tierras concejiles en la España del Antiguo Régimen», En Anes, G. La economía española del final de Antiguo Régimen. Alianza Editorial. Madrid, pp. 189-258.

\section{Fuentes}

ARCHIVO HISTÓRICO PROVINCIAL DE PALENCIA (AHPPA): Catastro de Ensenada, Libro de Respuestas particulares, Libro 740. Hacienda, Caja 4.884, año 1931.

ARCHIVO HISTÓRICO PROVINCIAL DE SEGOVIA (AHPSG): Hacienda. Administración de propiedades. Caja 1.922.

ARCHIVO HISTÓRICO PROVINCIAL DE VALLADOLID (AHPVA): Protocolos Notariales, Escribano de Castronuño L. Caballero Sánchez, Legajo 13.946-1, año 1752. Protocolos Notariales, Escribano Fco. Ignacio de la Rúa Vizcarro, Legajo 13.947; años 1769/1776. Concejil, Caja 238, expediente 19. Concejil. Caja 238, expediente 1. Licencias de cortas del monte de esta villa; año 1784. Hacienda, Expedientes de subastas, Caja 1.359, año 1859. Protocolos Notariales. Escribano Nicolás López. Legajo 5.829; año 1854. ICONA. Jefatura Provincial, Caja 455-2, año 1918. ICONA. Jefatura Provincial. Caja 232-3, año 1952. ICONA. Jefatura Provincial. Caja 455, año 1916. ICONA. Jefatura Provincial. Caja 448, año 1931). Hacienda, Administración, Caja 7.219, año 1931.

ARCHIVO HISTÓRICO PROVINCIAL DE ZAMORA (AHPZA): Catastro de Ensenada. Respuestas Generales. Libro 760.

ARCHIVO MINISTERIO DE AGRICULTURA (AMA): Memoria justificativa de los planes de aprovechamiento forestales de las provincias de Palencia, Valladolid y Zamora, de los años 1874 a 1875 . Cajas 5 y 10.

ARCHIVO MUNICIPAL DE PALENCIA (AMPA): Libros de actas municipales de los años 1865 a 1875.

ARCHIVO MUNICPAL DE TORO (AMTO): Caja 625, 11 (Relación del año 1806 con las roturas e intrusiones realizadas en el Monte Bardales y en el Monte Iniestas, realizada a efectos de deslindar, amojonar y saber el terreno que hay roturado en los citados montes).

ARCHIVO MUNICIPAL DE VALLADOLID (AMVA): Libros de actas municipales de los años 1760 a 1780.

ARCHIVO REAL CHANCILLERÍA DE VALLADODID (ARCHVA): Pérez Alonso (Olv.), Caja 559-2, año 1775. Pleitos Civiles, Pérez Alonso (F.), Caja 1.193-1, año 1606. Pleitos Civiles, Alonso Rodríguez (F.), Caja 3.059-1, año 1667. Pleitos Criminales, Caja 181-2, año 1827. Pleitos Civiles, Pérez Alonso (F.), Caja 120-1; año 1728. Pleitos Civiles, Alonso Rodríguez (D), Caja 602-1, año 1767. Pleitos Civiles, Alonso Rodríguez (F.), Caja 2.246-1, año 1750. Pleitos Civiles, Pérez Alonso (F.), Caja 3.021-6, año 1702. Pleitos Civiles, Pérez Alonso (Olv.), Caja 681-4, año 1791. Pleitos Civiles, Pérez Alonso (F.), Caja 3.557-1, año 1796. Pleitos Civiles, Pérez Alonso (F.), Caja 29-2, año 1579. Pleitos Civiles, Pérez Alonso (F.), Caja 341-1, año 1584. Pleitos Civiles, Pérez Alonso (F.), Caja 858-1, año 1586. Pleitos Civiles. Pérez Alonso (F.), Caja 1.141-1, año 1588. Pleitos Civiles. Zarandona y Walls (Olv.), Caja 541-1, año 1589. Pleitos Civiles, Pérez Alonso (F.), Caja 1.819-1, año 1607. Pleitos Civiles, Pérez Alonso (F.), Caja 2.241-3, año 1632 . 